\title{
Empathic Communication in the Process of Teaching English OSADCHA Elena
}

\author{
Oles Honchar Dnipropetrovsk National University, Ukraine \\ E-mail address: elena.osadcha@gmail.com
}

Keywords: empathy, empathic communication, empathic listening, English teaching

\begin{abstract}
The aim of this study is to analyze the ways empathy influences the effectiveness of the process of teaching English. The problem of empathic communication in the educational process is considered. The genesis of the concept of empathy is traced in behaviorism, psychoanalysis and in humanistic psychology. The aspects of empathy are distinguished and characteristics of the empathic process are determined. The role of empathy in the educational process and in the teacher's behaviour is described. The significance of empathy in intercultural communication of English learners is assessed.
\end{abstract}

\section{INTRODUCTION}

Empathy is an extremely complex concept which may mean understanding emotional states of another person, the psychological process which makes it possible to understand the feelings of someone else, the action of building up communication in a specific way, the ability to penetrate into the psychological state of a person one contacts with. Empathy is the readiness to the emotional response to the feelings of another person. It has cognitive, affective and behavioral aspects and facilitates successful communication and interaction.

"Empathy necessitates some level of emotional regulation to manage and optimize inter subjective transactions between self and others. The emotional state generated by the perception of the other's state or situation needs regulation and control for the existence of empathy" [1]. Empathy is an essential quality of a teacher of English because only through the empathic communication it is possible to organize a complicated process of acquiring habits and skills of a foreign language. This process is characterized by the increased anxiety of students which can be relieved or even removed as far as possible by an empathic teacher.

\section{DEVELOPMENT OF THE CONCEPT OF EMPATHY}

A great Russian writer Leo Tolstoy wrote: "The best man lives by his own thoughts and the feelings of others, the worst one - by his own feelings and the thoughts of others. The rest of the mankind is somewhere in the middle". So, empathy is not a common quality and not all people have it in the equal degree. One of the Russian educators, Vasil Sukhomlinsky shared this idea: "The one who is deaf to others will be deaf to himself'. This shows the importance of empathy in human relationships, activities and communication. It is impossible to understand oneself without understanding others.

Empathy was interpreted in different ways. Behavioral understanding of empathy is presented by two opinions. The first one is based on the idea that any learning is carried out by confirmation which may be positive or negative. The behaviour of an individual is defined by the environment, but not his psychological state. The second one is connected with the imitation of the positive model. Learning various feelings starts with the parents' praise which gives the sense of pleasure to a child. The behaviour that is constantly praised is reinforced and repeated later on

In psychoanalytical theory, Freud stressed the role of empathy in socialization, explained its mechanisms as those connected with identification. Identification is the basic component of socialization, the unconscious imitation of adults' behaviour by a child that enables him to acquire the morals norms of the society. According to Freud, to be empathic means to perceive the subjective world of another person not forgetting that you are a different one. 
Forming and developing empathy begins at an early age, when a child starts to understand that there are not only his own desires and needs, but also those of other people. This process is known as decentration. This concept was introduced by Jean Piaget. Decentration is opposite to a child's egocentrism and is considered as a child's need of the interaction. The condition of interaction is to take into account the opinions of others.

American psychologists at the beginning of the $20^{\text {th }}$ century made great contribution into the investigation of empathy. They gave it a social status, showed its regulating function (enhancing relations between people), defined the interrelations between the emotional perception and physical behaviour of a person. They distinguished cognitive, affective and behavioral aspects of empathy and its psychological mechanisms.

\section{MAIN ASPECTS OF EMPATHY}

Humanistic psychology and its representative C. Rogers gave a new impulse for developing understanding of empathy. Empathy was considered in the context of psychotherapy, later - in the real practice of educational process and family life. C. Rogers defined empathy as a way of coexisting with another person, entering his inner world and being comfortable in it. It meant to be sensitive to the changes of feelings that constantly go on in another person. The client-centered approach to psychotherapy is based on this concept. There can't be any stereotypes and prejudices. It is extremely important for the psychological well-being of a person. Experiencing the feeling of being understood and accepted contributes greatly to the personal growth. Humanistic philosophy suggests that it is empathic listening, not explaining that has a therapeutic effect on a client. This approach was projected by Rogers on other areas of communication: a teacher - a student, a child a parent. It implies that not only a psychotherapist, but a teacher, a parent and a spouse can improve the personal growth, communication and learning.

The analysis of the psychological literature on the problems of empathy enabled us to distinguish 4 basic approaches to its investigation in psychology:

- affective, where empathy is considered as an ability to accept the feelings of another person and sympathize with him in the process of interpersonal relationships;

- cognitive, in which empathy is considered as a cognitive ability to recognize the emotional condition of the other;

- practical and behavioral, where one can respond to the feelings; it is connected with the reflection of his inner condition, thoughts and moods;

- integrative, which means the combination of emotional and cognitive processes.

Development of empathy as a moral quality is closely connected with the social environment. At an early age a child actively acquires the knowledge of moral values and norms. Firstly it goes through the emotional and evaluational level, then through the behavior which is formed on the basis on these norms. Thus, empathy is reflected in the system of social relationships and gradually becomes a personal quality.

C. Rogers and his followers distinguished the specific features of the emphatic process:

1) the dynamic character of the emphatic understanding (Empathy is a process, rather than a state):

2) preserving the feeling of "as if another person";

3) the lack of assessment in empathic understanding;

4) the probation character of empathic remarks, (only hypotheses);

5) the actual feelings as the main aims of empathic understanding;

6) conveying empathic understanding to a person as a necessary condition.

\section{EMPATHY AS A QUALITY OF A TEACHER}

The interest of educators to empathy has historically centered on teacher empathy. Carl Rogers compared a teacher to a psychotherapist and a student - to a client.

Teachers very often face the need to tune themselves to another person in order to make the necessary influence. It is very important for this influence nor to be superfluous, but to penetrate 
into the inner word. Teachers aim at making deep changes in their pupils, keeping in mind that one of the principles of their work in not to do any harm to pupils. Teachers have a great variety of means of influence. And one of them is the influence through sympathy and sharing feelings.

Humanistic essence of the educational activity is fully disclosed in the context "a teacher - a student". A teacher should see the world with the students' eyes. Otherwise, cooperation would be impossible. This professional vision is developed on the basis of the personal quality of a teacher empathy. It is an integrated ability containing a rather high level of sympathy and attention to another person.

It was found out that a highly empathic teacher forms in his students such qualities as autonomy, self-control and responsibility for academic results. While acting in an empathic way, a teacher should not subordinate a child, but ensure the autonomous way of a child's development on the basis of pedagogical involvement.

Empathic communication of a teacher and a student is characterized by:

- equality of psychological positions, activeness of parties;

- mutual penetration of partners into the world of feelings and sensations;

- readiness to accept another point of view;

- desire to sympathize and share feelings;

- active disposition of partners.

Empathic educational communication is a specific activity of a teacher that is manifested in the form of emotional contact of a teacher and a student, each element of which has an emotional constituent.

C. Rogers stressed empathy as a quality of a facilitator, the one who enhances the process of learning. His team conducted large scale (600 teachers and 1000 students) investigation which showed the role of empathy in teaching and upbringing. Students who had highly empathic teachers demonstrated:

- fewer cases of missing classes;

- more personal autonomy, less physical and verbal aggression;

- more developed self-concept;

- less problems with discipline;

- higher IQ;

- creativity of thinking.

M.L. McAlinden distinguishes the following aspects of teacher empathy: knowing, motivation, seeing, tolerance and understanding. But what are the conditions required for the development of these aspects? They are divided into two groups: understanding through experience and connecting. The first condition includes getting to know students, being in control and shared experience. The second condition includes caring and communicating [2]. An English teacher can not be distracted and indifferent, not interested in students' life and problems. The process of learning a foreign language provides a lot of methods that create various situations for communication. There are role plays, simulations, project methods, discussions which require not only the knowledge of English as a system but also the personal involvement of students. All educational materials such as texts, dialogues, books, audio and video materials always contain an intellectual and emotional message which is impossible to grasp without empathy. Emphatic student is able to understand the plot, the character and the motives better if he can feel into the situation suggested in the text. Only on this condition it is possible to build a free discussion where the accent is not on the lexical units and grammar structures but on analyzing and making conclusions in the target language.

According to M.L. McAlinden [2], being an effective teacher means 3 things: 1) caring about students (helping them, encouraging and motivating), 2) reflecting on practice (planning lessons, knowing methods, learning by experience) and 3) attending to students' needs (listening to students, talking to students and responding to students' needs). 


\section{EMPATHIC COMMINICATION IN TEACHING ENGLISH}

Educational readiness of a person for the professional activity should be characterized by the high level of cognitive, emotional and behavioral components. Developing empathy in teachers supplies them with the necessary tools to understand both themselves and their pupils in the process of educational interaction. Empathy enables a teacher to see what caused student's behaviour, creates a special emotional background that helps both a teacher and a student to realize their potential. Empathy becomes a personal quality when its components create a whole system.

The situation of understanding occurs in case when an individual has a problem and can not connect and interpret it in the available terms. In this case his behavior becomes controversial.

Teaching at natural faculties, where English as a foreign language is not a major and students have a rather low level of it, we often face the situation when students don't show good knowledge of English, whereas they have a rather high level of academic achievement in their core subjects. As a result, they feel frustrated and disappointed. They may even begin to miss classes and neglect their homework. It is very important to encourage the students by choosing the tasks that are creative and make them feel success no matter how tiny it is. It may prove helpful to discuss any possible changes in the curriculum and tailor it to the needs and interests of students.

Empathic teacher will never constantly point out mistakes and comment on the lack of knowledge. Instead, he will model the situation where students will "spread their wings" and take challenging and difficult tasks. Every year the Department of Foreign Languages for Technical and Natural Specialities in Oles Honchar Dnipropetrovsk National University (Ukraine) holds a conference in foreign languages on the actual problems of science. Students willingly take part in it. All students are invited notwithstanding their level of English. This is a real case where students feel that a good command of a foreign language is necessary for a young scientist and develop motivation to study and achieve success. Teachers are involved in individual work with students, give them encouragement and support. There are creative groups in which students have a good opportunity to discuss the articles they are going to submit with their group mates. These are good examples when in the educational process the accent is shifted from just acquiring knowledge to its practical application and gaining confidence.

Here we will pay attention to the moral and psychological conditions of effective communication in the process of teaching English. Morality in the context of communication is the dimension that defines the teacher's behaviour, his attitude to students, the manner of speaking, the internal need of an individual to act. The humanization of communication is the ability of a person to sympathize and share feelings. Besides, humanization includes democratic relationships, respect to a partner and self-respect, social justice and tolerance, unprejudiced attitude to the partner and taking into consideration the interests of students. It is especially important for a teacher of English, because, as psychologists say in their studies, the process of learning English is characterized by a high degree of students' anxiety. All kinds of language activities (reading, writing, listening and speaking) involve different psycho-physiological mechanisms: perception, long-term and short-term memory, anticipation, the level of attention concentration. Attention is closely connected with emotions, the novelty of the material, and realizing the objective need to study and acquire new knowledge. So, motivation is extremely important. Depending on the individual psychological features and the state of a student, information can be perceived differently: it may be understood deeply and clearly, or it may be misunderstood. The task of a teacher is to organize educational activity and communication in such a way that will help student feel confident, motivated, concentrated and relaxed.

Harden and Grosby point out 12 teacher's roles grouped in 6 areas:

1) the information provider;

2) the model;

3) the facilitator;

4) the assessor;

5) the planner;

6) the resource material creator [3]. 
This classification enables us to see the multiple roles a teacher plays in the classroom and a wide range of preparatory work to be done to organize the process of learning. Only empathic teacher is able to analyze the needs of students, plan the activity and make a step to cooperative learning. So, the responsibility for effective learning rests with a teacher.

Empathic listening is a kind of listening which gives a sense of relief to another person and opens the new ways for understanding his own feelings. It helps the one who listens share the feelings of the other and understand his emotional state. Empathic listening implies neither giving advice or assessments nor criticism or reproach. Psychologists formulated 4 rules of emphatic listening:

1) to break free from one's own emotional experience and prejudices as for an interlocutor;

2) to show that the feelings of an interlocutor are acceptable for you;

3) not to give any interpretation to his behavior;

4) to take a pause to let a person keep silent, without filling this pause with judgments and explanations.

If we project these rules on the educational process of teaching English, we will understand that empathic listening is very important. In the process of forming different language habits and skills, a student may have difficulty finding a right word or a suitable grammar structure. There is some uncertainty as for the pronunciation of words and word combinations. A teacher should be able to relieve this anxiety with the help of empathic listening. It is important to be considerate and tolerant, not to criticize a student, not to interrupt with by giving prompts and correcting mistakes. Only patience is required to understand thoughts and ideas from the students' point of view. Empathic listening creates empathic learning environment. Empathy is an attribute of those that has proven to be highly relevant to the educational process and educational outcomes [4].

\section{EMPATHY IN INTERCULTURAL COMMUNICATION}

In the process of learning English great attention is paid to forming the competence of intercultural communication. In the modern world the language training of a specialist is connected with the development of the abilities to apply a foreign language as a tool of communication in the dialogue of cultures. A lot of investigations have been focused on the problems of forming intercultural competence. It may be formed with a text as a basis, in the process of communication in a foreign language or with the help of role plays and simulations. The process of learning about the customs and traditions of other countries, the way people live and communicate and the analysis of the social problems contributes to the successful formation of the intercultural competence. The crucial significance in this process is attributed to forming strong and conscious positive identity, cultural tolerance, mutual understanding and the search of similarities and differences. Empathy and tolerance are the basic constituents of this process. Tolerance is the principle which recognizes the moral value and a quality of a person and readiness to accept him. Empathy is the ability to feel into another person with the aim of understanding his feelings and thoughts. A. Maslow considered empathy to be the main way of self-actualization of a person and one of the conditions for his selfimprovement. A student can distinguish between his own culture and other cultures, take up new roles and feel comfortable in different areas of the other linguistic and cultural society.

Teachers of English have to work with culturally diverse students. Sometimes they do not display a high level of empathy. G. McAllister [5] suggested the way of improving teacher empathy by involving them in an experiment. The experiment included: a) involvement in the cross-cultural simulation as a visitor to another country; b) immersion in a cultural community when teachers had to visit the homes and families of minority students; c) reflection on their own experiences. Their comments after this experiment reflected empathic dispositions and behaviours. They experienced mixed feelings which made them give more thoughts to the students they teach and change their teaching strategies because of using more empathic behaviours. Their own experience prompted to change classroom interaction, create supportive environment in the classroom and helped to foster empathy. 


\section{CONCLUSIONS}

Empathy is considered an important quality of an English teacher. It is an integrated ability containing a rather high level of sympathy and attention to another person. Empathy includes cognitive, affective and behavioral aspects. The interest of educators to empathy has historically centered on teacher empathy. C. Rogers defined empathy as a way of coexisting with another person, entering his inner world and being comfortable in it. This approach was projected on the area of educational communication. C. Rogers' investigation showed the role of emphatic teachers in academic achievements, behaviour and motivation of students. In this research it was shown that the process of learning a foreign language provides a lot of methods that create various situations for communication. Emphatic communication implies democratic relationships, respect to a student and self-respect, social justice and tolerance, unprejudiced attitude to students and taking into consideration their interests. The analysis proved that psycho-physiological mechanisms involved in the process of foreign language learning will function properly in a supportive and friendly classroom environment. The study revealed that empathy and tolerance are the basis of intercultural communication. It was proved that only empathic teachers can work effectively with culturally diverse students. This problem of empathic communication in very important and there remain some aspects that need further studies.

\section{References}

[1] N.Eisenberg, N.D. Eggum, Empathic responding: Sympathy and Personal Distress, in: J. Decety, W. Ickes (Eds.), The Social Neuroscience of Empathy, Massachusetts Institute of Technology, 2009, pp.71-73.

[2] M.L. McAlinden, Beyond understanding: intercultural teacher empathy in teaching of English as an additional language, The University of Western Australia, 2012, pp 90-100.

[3] R.M. Harden, J.R. Grosby, The good teacher is more that just a lecturer - the twelve roles of the teacher, Medical Teacher, 22 (4), pp. 334-337.

[4] N. D. Feshbach, S.. Feshbach, Empathy and Education, in: J. Decety, W. Ickes (Eds.), The Social Neuroscience of Empathy (Eds.), Massachusetts Institute of Technology, 2009, pp.8587.

[5] G. McAllister, J.J. Irvine. The role of empathy in teaching culturally diverse students., Journal of Teacher Education, vol.3, 5(2002), pp. 433-443. 